\title{
Virtual thanks giving to a cadaver by medical students exposed to learning anatomy before and amidst COVID-19 pandemic
}

\author{
Anjali Singal $^{1}$ (D) $\cdot$ Daisy Sahni $^{2} \cdot$ Priti Chaudhary $^{1} \cdot$ Harsimranjit Singh $^{1}$
}

Received: 14 December 2020 / Accepted: 12 February 2021 / Published online: 25 February 2021

(c) The Author(s), under exclusive licence to Springer-Verlag France SAS part of Springer Nature 2021

\begin{abstract}
Purpose Due to COVID-19 pandemic, Thanks giving ceremony to cadaver was different this year in two ways: the students were partially exposed to cadaveric dissections (for 7 months) and later learned Anatomy via online classes due to lockdown (for 5 months) and secondly it was not feasible to gather for the ceremony so virtual platform was preferred. The purpose of this study was to discern the gratitude for cadaver and to recognize the importance of cadaveric dissection from the reflection of students who experienced hybrid anatomy learning amidst COVID-19.

Methods The study was conducted on 48 first year medical students who were admitted to the college in August 2019 and were willing to participate. An online invitation was sent to students to participate in virtual thanks giving to cadaver ceremony on the last day of their anatomy class (August 2020).

Results Though the students partially studied gross anatomy with the aid of dissections on the cadaver; however, they expressed respect and gratitude to the silent mentor in the form of a card, poem, drawing or paragraph and shared it via google classroom platform. The students wished if they could continue their anatomy course in dissection hall as paused due to COVID-19 pandemic.

Conclusions Reflection of these students may mark impact on future anatomy students who may or may not get the chance for dissections. The thanks-giving gesture will also help to bind medical science and humanity especially during the crisis of pandemic.
\end{abstract}

Keywords COVID-19 $\cdot$ Dissection $\cdot$ Gratitude $\cdot$ Silent mentor $\cdot$ Thanksgiving $\cdot$ Virtual

\section{Introduction}

The human cadaver is a silent mentor that imparts knowledge and allows three dimensional visualization of amazing architecture of human body. The hands-on-experience derived from cadaveric dissection is incomparable to any other mode of anatomy learning [2]. It's the moral responsibility of the anatomy students to handle the cadaver with utmost care. To inculcate the basic bioethics for cadaver handling in newly joined medical students, cadaveric oath taking ceremony is performed on the first day of the dissection course in most of the institutes globally $[2,6,8]$. The

Anjali Singal

anjali_singal@rediffmail.com

1 Department of Anatomy, All India Institute of Medical Sciences, Bathinda, Punjab 151001, India

2 Department of Anatomy, Postgraduate Institute of Medical Education and Research, Chandigarh, India students pledge to show respect and gratefulness towards the cadaver. After the completion of dissection course, funeral services have been incorporated by some medical schools and to pay gratitude to silent mentor "Thanks giving to cadaver" ceremony has been conducted by many institutes from more than two decades $[2,4]$. Such ceremonials also provide opportunity to remember the person who dedicated his mortal remains for the advancement of medical education and research.

In our set up, the new session for MBBS first year commenced in August 2019, the students attended the anatomy classes through dissection hall, labs and face to face lectures for almost seven months (till March, 2020) and afterwards via virtual classes because of world-wide lockdown and university closures. The students completed their anatomy course in August 2020 and it was the time to thank the cadaver, however due to global health crisis of COVID-19, the students were still not in the campus, so unconventional 
tribute to the cadaver "The Virtual Cadaver Thanks giving" was planned.

The students of pre-pandemic era, had the experience of dissecting complete human body and the forthcoming batch or till the pandemic is over, the students may have to continue via digital platform. The authors feel that the anatomy education practice of this batch of students is unique, as they experienced hybrid Anatomy education; cadaveric dissections as well as non-cadaveric virtual anatomy classes. The objective of the current study was to discern the gratitude for cadaver and to recognize the importance of cadaveric dissection from the reflection of students having experience of cadaveric dissections and virtual anatomy learning via virtual Thanks giving to cadaver ceremony.

\section{Materials and methods}

Forty eight first year medical students from All India Institute of Medical Sciences, Bathinda participated in the current study. Though fifty students were admitted to the institute in August 2019 however only the students who gave their consent and were willing to partake in the study were included. The students belong to age group from 17 to 20 years (mean age 19 years; 18 female and 30 male). They were informed about the Virtual thanks giving to cadaver Ceremony. An invitation was sent to the students in google classroom on the last day of their anatomy course in August 2020 to express their feelings and gratitude for cadaver in the form of a card, collage, painting, poster, poem, quotation or some paragraph in English or native language. They were supposed to post the responses within 10 days of this invitation. Each response was sorted according to language and type i.e. either poem, paragraph, collage, poster or drawing and analysed thoroughly.

\section{Results}

The students participated enthusiastically in "The Virtual Cadaver Thanks giving" ceremony. They expressed gratitude to the silent mentor in the form of a Thank you card (five students), poem (four students), diagrammatic creation (five students), paragraph (34 students) and shared it via google classroom platform. Every reflection and response was unique in its own way. Four of the reflections were written in native language.

\section{Student's reflections}

The students expressed respect and gratitude towards the cadaver in their message and wished if they could continue their Anatomy course with the help of cadaveric dissections, which was paused because of COVID-19 pandemic. Some of the student's reflections are as mentioned below:

Student "a": Letter to cadaver (translated from native language; the authors feel that mother tongue provides the opportunity to express one's feelings in an unpretentious way).

Dear cadaver "Though virtual classes were going on, however I missed the dissection part a lot. There is fresh memory in my mind, how we studied the gross anatomy of Thorax, upper limb, Head \& neck and Brain (partly) with your generous help. During my training period, we have to cut your ribs, orbit and so on...but you bear with us, as you are a great man, who served the humanity even after death. Please forgive me. Today during pandemic period, virtual dissection is much in discussion, but the moments I have spent with you in the dissection hall, is the real experience of learning Anatomy."

Student "b": Tribute to cadaver-an ode.

Dear Cadaver,

"I am a student of Table number four,

Here to narrate my journey with you from my deep-

est core.

I still remember the first day of dissection,

So scared, feared as I would vomit or might get an infection.

But it all went away the moment I made my first cut on you,

Can never forget that adrenaline rush inside me;

How it all felt was so untrue.

After that there was no looking back,

Neither anything could push me aback.

I recall the days, when we dissected upper limb,

Then came Thorax where I got sick,

Couldn't do dissection and got all the details in my

head mixed.

That feeling of holding your heart and brain was so magnificent,

Wish could have seen other organs (of abdomen) too, Oh! This Corona pandemic

Imagining the days when formalin or blood would stain my coat,

But sheer joy of exploring your entrails wouldn't stop me to take note.

It is difficult to convey my respect for thee,

Because it is you who kept me enthralled in Anatomy. Highly appreciable job you did by donating your corpse;

Instead of lying in a grave or scattering the ashes near a shore.

Great contribution you have made to humanity, educating future doctors of country; 
Here's a promise I make to you, your journey after life would not go in vanity!"

Student "c" expressed as "I found it strange when during the first day of dissection hall, my teacher addressed that this is the place where dead teaches the live. Though I could not actually accept the same, however I was able to understand these words soon after spending few hours in dissection hall. I feel gratitude for your sacrifice."

Student "d" expressed as:

"Dear cadaver,

First day of dissection

Fascinated was I, like all other medicos

That strong pickling formalin smell, gave me tears

Little did I know their value in later years?

Owing a dissection kit was new charm

Using scalpel on you, proved no harm

Student "e": Beautiful drawing (Fig. 1) depicting the transmission of anatomical knowledge from silent mentor to student's brain and mentioned that the cadaveric dissection helped to clear the three dimensional concepts of human body.

The student " $\mathrm{f}$ " inspired by the sacrifice of donor stated that "I will dedicate myself to provide the best treatment to my patients."

The students thanked the cadaver and truly appreciate the opportunity they acquired to gain in-depth knowledge of even the minute structure of human body during their dissection classes.

\section{Discussion}

Most of the anatomy programmes include dissection of donated human bodies [4]. Different Anatomy departments pay respect and gratitude to this great teacher by holding various events like memorial services, cadaveric oaths, release of red balloons with messages to body donors, cadaver thanks-giving ceremony and in some institutes the students are even informed of the identity of the cadaver and they visit the family to show gratitude for the special gift the body donation $[4,6,14]$. The consideration and inclusion of such ceremonies are a significant step in Anatomy fraternity, as the students would be acclimatized to comply with the chief ethical standards as they prepare to serve the precious human lives $[2,13]$.

To inculcate the respect and gratitude for cadaver among our anatomy learners, the anatomical education commenced with the cadaveric oath taking ceremony on the first day of their dissection lab. The students attended the dissection hall lab for almost ten hours a week for nearly 7 months till the late March, 2020. They dissected upper limb, thorax, head and neck and brain (partially) on the cadaver. In March when mandatory lockdown was announced in the country to contain the spread of COVID-19, all the educational institutes
Fig. 1 Drawing by Student "e" indicating the easy and effective subject understanding with the help of silent mentor

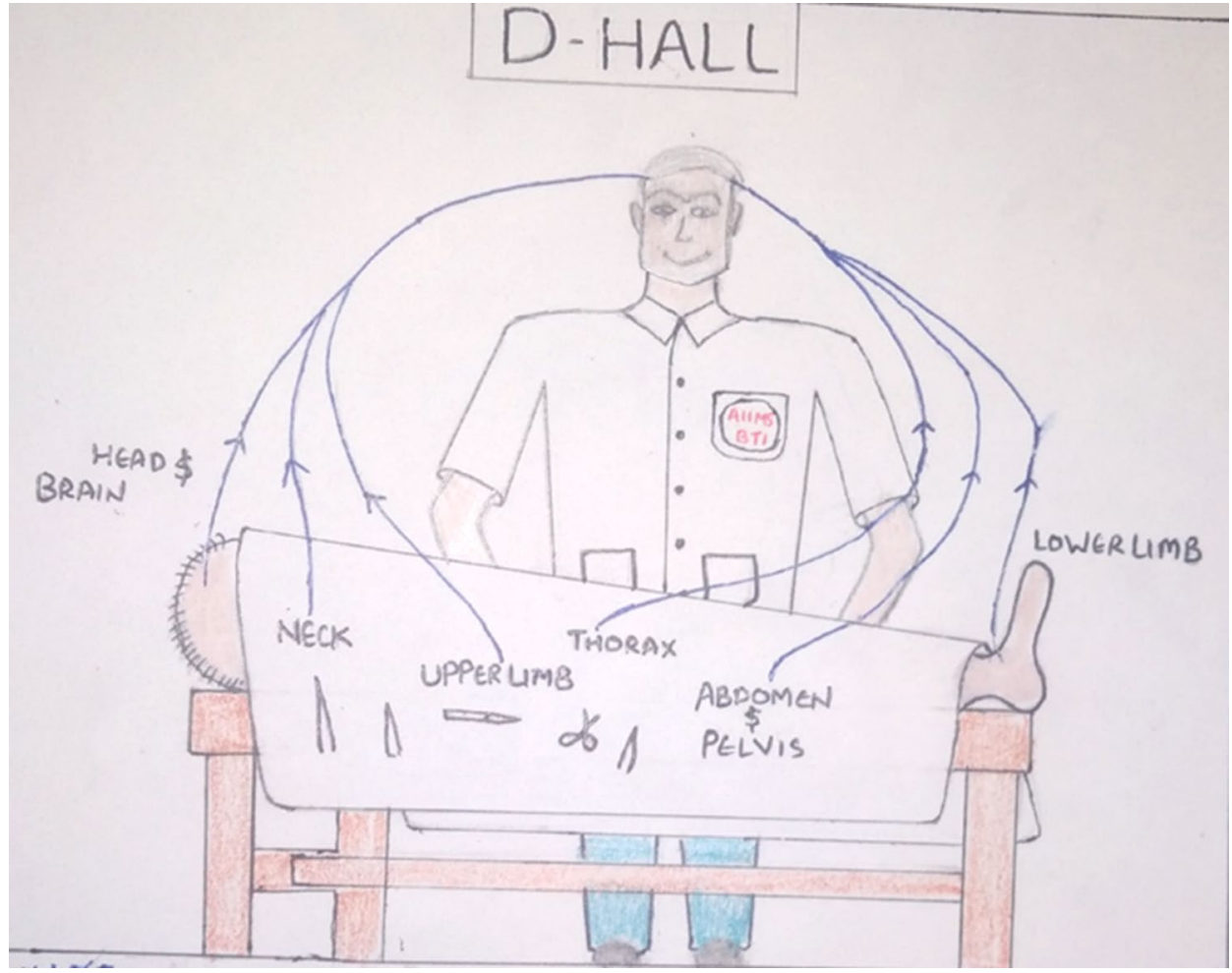


including medical colleges were closed. The digital platform was the only option to continue anatomy education and was planned with least delays [12]. After attending virtual classes for almost 5 months, the students completed their anatomy course in August 2020 and it was the time to thank the cadaver. Though a number of previous studies talk about honouring and thanking the cadavers in different ways $[1,4,7,8]$ and typically such ceremonies range from informal, private gatherings held in Anatomy laboratories to large convocations that may include donors' family members $[3,8]$. However due to global health crisis of COVID-19, on-line tribute to the cadaver "The Virtual Cadaver Thanks giving" was planned. Such gestures create the responsibility to reciprocate this ultimate gift of a human body to medical education with respect, compassion and dignity and help to bind medical science and humanity more strongly especially during the crisis of COVID-19 pandemic [5]. The authors feel that Thanks giving to the cadaver was also inimitable this year (2020), as the thank you messages were from the students with hybrid anatomy learning experience. The students realised the true importance of cadaver as they could not avail the opportunity for complete cadaver dissection.

\section{Invisible relation between medical student and cadaver}

The first visit to dissection hall is a memorable experience for every medical student. To some, it's the formalin smell that never fades away, for others it is unbearable to see dead body and some may feel that they have joined this profession to see life, not a dead human body [10], but gradually an invisible relationship develops between the student and the silent teacher "the cadaver". This relation was in the process of creation when the pandemic COVID-19 emerged, ensuing the students away from their dissection labs.

\section{COVID-19 pandemic fixed cadaveric dissections}

The cadaveric dissection is an invaluable experience for understanding three dimensional gross structure of the human body in a stress-free environment. It helps the undergraduate students to develop not only surgical skills, but better physical examination of patients, diagnosis of disease and reliable interpretation of radiographs as well. The worldwide health crisis of COVID-19 pandemic, the lockdowns due to disease and institutional closures, stuck the cadaveric dissections to hold. Though the scenario was not intentional and the motto was not to make the students sense the importance of cadaver dissection and even it was not that students denied the importance of dissections, however the virtual anatomy classes during the pandemic forced them to recognize the true importance of dissections. The students appreciated that this learning tool mutely helped them to understand the subject very nicely and easily. As is aptly said "You don't realise the value of something till you have it."

\section{Unique partial experience of dissections and impact of non-cadaveric virtual classes}

It's the first ever while, that the students experienced both the methods of Anatomy learning i.e. with cadaver dissections and virtual classes. No one ever imagined in the initial phase of anatomy classes and dissection hall this year that they will continue their anatomy course via virtual classes. The impact of non-cadaveric virtual classes is clear from the reflection of the students. They wished if they could learn the gross topics covered via virtual classes with the help of their silent mentor. They recognised that the hands-on experience derived from dissecting cadavers can never contest the new generation digital learning techniques. The students' remorse that they could not even thank and say good bye to the cadaver in the dissection hall.

\section{Future plan: to create an honour wall “A Glorious Tribute to silent mentor amidst COVID-19 pandemic"}

As the reflection of first year MBBS students from 2019 batch are imperative, it has been planned to create a separate tribute wall in the museum and name it as "A Glorious Tribute to silent mentor amidst COVID-19 pandemic: 2019 Batch." The thank you messages from the students will be displayed here.

The current situation of COVID-19 pandemic may continue for unknown period, as no vaccination for this deadly virus is available so far and anatomists are stuck with cadaver-less virtual anatomy education option. It is envisioned that Anatomy education especially cadaveric dissections will not be same as it was during pre-pandemic period at least in near future because of pandemic and nonacceptance of bodies by Anatomy community [11, 12]. The responses and thoughts of this batch of students in their virtual thanks-giving ceremony may mark profound impact on the future Anatomy students to realize the importance of cadaveric dissections; as they may not get the opportunity to perform the same and to be valued by those, who will get the opportunity to dissect.

The Virtual Thanks giving ceremony to cadaver was a meaningful conclusion to the gross anatomy curriculum especially during pandemic COVID-19. The compassion, respect and gratitude for the silent mentor was well revealed from student's thank-you communications. Such gestures help to bind medical science and humanity more intensely especially during the crisis of COVID-19 pandemic. 


\section{Limitation of study}

The limitation of the present study is the small sample size and the thanks-giving messages are limited to specific institute and geographic region; however, this study makes foundation for integrated multicentre analysis.

Acknowledgments The authors sincerely thank the first year medical students who accepted our invitation to participate in the present study.

Author contribution AS project development, data analysis, manuscript writing. DS project development, data analysis, manuscript editing. PC data collection, data analysis. HS data collection, manuscript editing.

\section{Funding Nil.}

\section{Compliance with ethical standards}

Conflict of interest We have no conflicts of interest.

\section{References}

1. Eze O, Horgan F, Nguyen K, Sadeghpour M, Smith AL (2009) The 2008 anatomy ceremony: voices letter, poems. Yale J Biol Med 82:41-46

2. Ghosh SK (2017) Paying respect to human cadavers: We owe this to the first teacher in anatomy. Ann Anat 211:129-134

3. Hull SK, Shea SL (1998) A student-planned memorial service. Acad Med 73:577-578
4. Jones TW, Lachman N, Pawlina W (2014) Honoring our donors: a survey of memo-rial ceremonies in United States anatomy programs. Anat Sci Educ 7:219-223

5. Kahn PA, Gardin TM (2016) A student proposal for ethical guidelines in anatomical education: ethical and policy considerations. Clin Anat 29:60-64

6. Kantor SL (2010) A silent mentor. Acad Med 85:389

7. Kooloos JGM, Boli S, Vander Straaten J et al (2010) An altar in honor of the anatomical gift. Anat Sci Educ 3:323-325

8. Pawlina W, Hammer RR, Strauss JD et al (2011) The hand that gives the rose. Mayo Clin Proc 86:139-144

9. Prakash PLV, Rai R et al (2007) Cadavers as teachers in medical education: knowledge is the ultimate gift of body donors. Singapore Med J 48:186-190

10. Sheriff DS, Sheriff O (2010) The human cadaver: the silent teacher of human anatomy. Indian J Med Ethics 7:266. https:// doi.org/10.20529/IJME.2010.102

11. Singal A, Bansal A, Chaudhary P (2020) Cadaverless anatomy: darkness in the times of pandemic Covid-19. Morphologie 104:147-150. https://doi.org/10.1016/j.morpho.2020.05.003

12. Singal A, Bansal A, Chaudhary P et al (2020) Anatomy education of medical and dental students during COVID-19 pandemic: a reality check. Surg Radiol Anat. https://doi.org/10.1007/s0027 6-020-02615-3

13. Snelling J, Sahai A, Ellis H (2003) Attitudes of medical and dental students to dissection. Clin Anat 16:165-172

14. Vannatta JB, Crow SM (2007) Enhancing humanism through gross anatomy: a pre-course intervention. Med Educ 41:1108. https://doi.org/10.1111/j.1365-2923.2007.02889.x

Publisher's Note Springer Nature remains neutral with regard to jurisdictional claims in published maps and institutional affiliations. 